\title{
Research on the Construction of English Follow-up Courses Based on the Multimodality Theory
}

\author{
Yuan Wang ${ }^{1, a}$; Dan Zhou ${ }^{2, b, *}$ \\ ${ }^{1}$ Wuhan Textile University, Wuhan, 430073, China \\ ${ }^{2}$ Wuhan Textile University, Wuhan, 430073, China \\ aemail: 102171977@qq.com; bZhoudan@wtu.edu.cn
}

Keywords: Multimodality, Appraisal, The construction of follow-up courses.

\begin{abstract}
Taking the classroom teaching discourse of the course Exploring English-speaking Countries as a case example, this paper discusses the theoretical guidance and practical significance of the multi-modal appraisal meaning construction on the development of English follow-up courses. Empirical studies have found that teachers' proper insertion of words containing positive significance, engagement significance and graduation significance was helpful to guide students to participate in the construction of meaning. Blackboard writing and PPT materials realize the engagement significance of visual resources; teachers' eye contact, facial expressions and gestures realize the contact significance, attitude significance, engagement significance and graduation significance of visual and body resources. Students' participation realizes attitude meaning. Teachers' positive emotional involvement and interpersonal interaction by mobilizing multi-modal resources play a role in promoting the construction of English follow-up courses.
\end{abstract}

\section{Introduction}

With the rapid development of science and technology in the past thirty years, new discourse phenomena and communicative approaches have constantly brought opportunities and challenges to the field of education.[1] Multimodality and Multiliteracy have become a new topic for language scholars and educators at home and abroad. Taking English follow-up course is an effective way to develop non-English Major Students’ English learning ability. [2] After the completion of College English basic education, the opening of follow-up courses can encourage students to continue to learn English, improve their cultural literacy and language communication skills. [3] In the process of classroom teaching, as long as teachers are good at using multimodal symbols resources, guiding students to actively involve their emotion, participating in knowledge construction, the teaching will finally get twice the result with half the effort. Taking the Martin's appraisal system and Kress \& Leeuwen's (2006) visual grammar as the theoretical framework and classroom teaching of the course Exploring English-speaking Countries as case example, this paper empirically studies how multimodal appraisal system achieve the interpersonal significance of various resources and promote classroom teaching in the process of constructing English follow-up courses.

\section{Theoretical framework}

Appraisal locates in the level of discourse and meaning of interpersonal meaning system (Martin 2005:33). Appraisal resources are used to negotiate social relationships, that is, to inform readers or listeners about our feelings and attitudes towards people and things (Martin 2007:26). The selection of appraisal resources and the production of appraisal meaning are related with three sub-systems: attitude, graduation and engagement. Attitude meaning consists of three types: affect-positive or negative feeling; judgment-judging others' behaviors; appreciation-positively or negatively judging others. Graduation meaning is the classification of attitude intensity, which 
consists of two types: force and focus. Force can be achieved through four ways: intensifiers, attitudinal lexis, metaphor and swearing. Besides, force can go rising and lower. Focus is the fuzzification of judging something, which can be sharpened or softened. Engagement meaning is related with the source of attitude, which can be divided into monogloss and heterogloss. Heterogloss can make more participants engaged in the discourse by projection, modality and concession.

Table 1 Framework of Appraisal system（Martin\&Rose 2007:59）

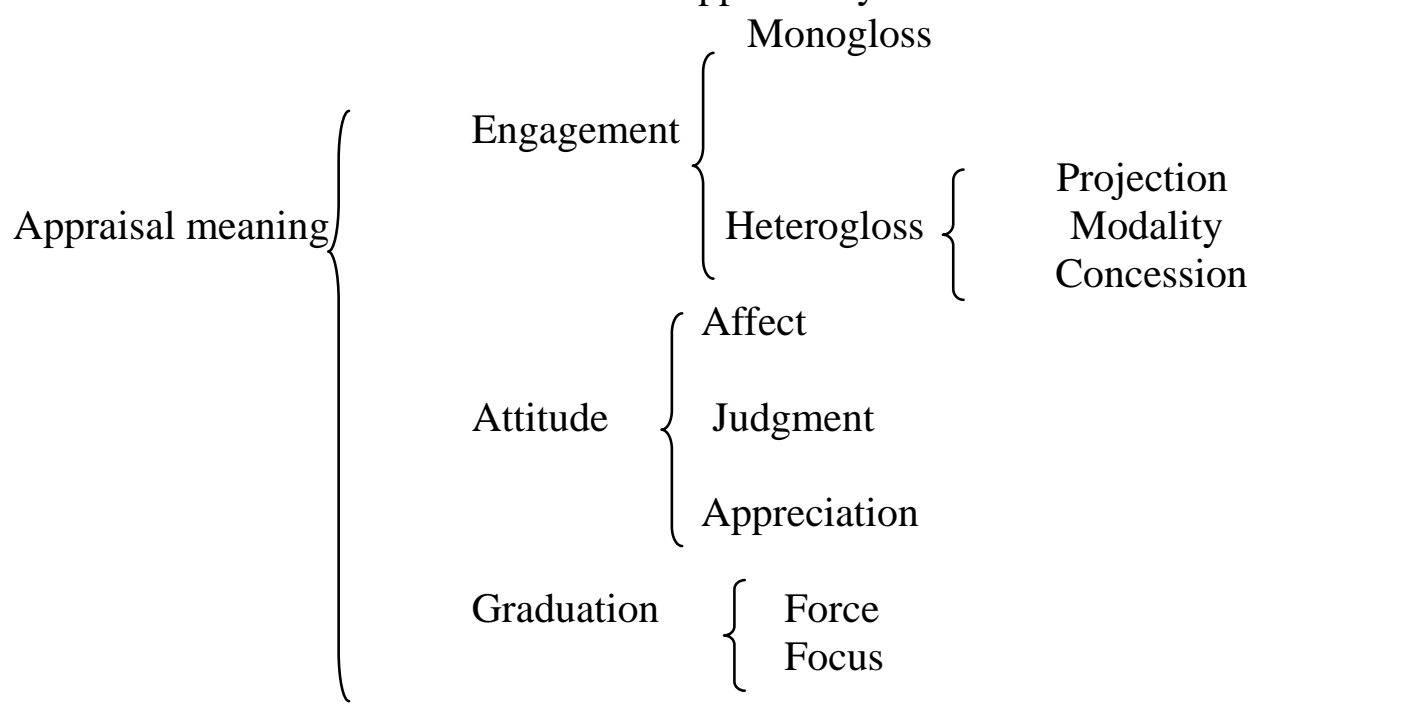

\section{Examples of multi-modal appraisal meaning construction in classroom teaching}

Taking the follow-up course Exploring English-speaking Countries as an example, using classroom teaching video recording data and questionnaire, this paper analyzes the multi-modal appraisal meaning construction of classroom teaching discourse and its role in the future English follow-up courses construction. The object of the study is a 45-minute course which introduces Britain including its national survey, geographical location, weather and major cities. In this class, there is one teacher, 186 students who are not from English major and from four different grades. The classroom teaching discourse is dynamic and multi-modal, which consists of teacher's verbal language(teaching and asking),written language(blackboard writing),facial expression and body gestures; students' verbal language(answering and speaking), facial expression; PPT materials(words, pictures and videos) and classroom settings, etc. This paper will have appraisal meaning analysis from four main modalities, that is, verbal resources, visual resources, gesture resources and space resources.

\subsection{Attitude meaning}

In terms of written language resources, there are three attitudinal meanings in the PPT text: leading, important, enjoy. In the aspect of oral language resources, the whole classroom discourse is mainly taught by teachers, and the words which express attitudinal meaning are unique, attractive, and impressive and dislike. There were no appraisal words in students' speeches.

(1) teacher: (London is) one of the world's leading banking and financial centers.

(2) teacher: Tourism is one of Scotland's most important industries.

(3) teacher: Tourists from the entire world come to enjoy the beauty of Scotland.

In terms of the part of speech of these attitudinal words, there is one in affect class, one in judgment class: enjoy and dislike. Affect is the direct expression of feeling; judgment is to judge others' behaviors. In this introducing Britain class, the occasional feeling expression and personal judgment of teacher would suddenly make students' impressions on this country be active which is helpful to students' knowledge construction. The words in appreciation class are: leading, important, unique, attractive, and impressive. Appreciation is also the judgment of something. When teacher 
objectively described the weather and cities of Britain, the appropriate explain of personal feeling and experience would be helpful to activate students' interests in involving in meaning construction. In all attitudinal meaning language resources, the positive meaning words are obviously more than negative meaning words. The classroom teaching should mainly focus on positively transferring knowledge and cultivating students' positive values.

\subsection{Engagement meaning}

Engagement meaning reflects two ways of the resources of attitude: monogloss and heterogloss. Monogloss means the speaker only provide one stand of his value; heterogloss concludes more values and more stands. After the statistics, the written language resources in this classroom teaching discourse-blackboard writing and PPT text belongs to monogloss engagement; oral language resources - the teaching of teachers and students, which consists of a total of 1570 sentences, about 59\% are monogloss engagement, 25\% are heterogloss engagement. Monogloss is the most common and most widely used way to teach knowledge in class, which shows the uniqueness of attitude and ensures the authority of the knowledge. There are three way to achieve heterogloss engagement meaning: projection (sentence 4), modality (sentence 5) and concession(sentence 6).

(4) teacher: as the picture indicates, Britain consists four parts: England, Scotland, Wales and Northern Ireland.

(5) teacher: According to 2012 census data, the population of Britain is about 60 million.

(6) teacher: The English population accounts for at least $40 \%$ of the total population of Britain.

Teacher introduces authoritative data and conclusions into the classroom teaching by projection which enhances reliability and persuasiveness. Regardless of monogloss or heterogloss, the basic objective of engagement meaning to strive for the unity of values between teachers and students, and attitude negotiation in the process of teaching.

\subsection{Graduation meaning}

Graduation meaning is the center of appraisal system (Martin 2007:36) which classify the attitude meaning and engagement meaning. Graduation meaning has two types: force and focus. Considering the teaching discourse in this classroom, which mainly refers to more than ten kinds of graduation meaning words of teacher's oral language and PPT text, the force can be sharpened and softened through two ways: intensifiers(relatively, very, most, all)and attitudinal words(rich). These graduation meaning words are the reflection of force in terms of quantity and extent, which is helpful for teachers to hold the intensity of using attitudinal words in his teaching process and enhance the inclusiveness of these words' values. Some graduation meaning words which soften its force like "about, equal to, completely, seem to" blur the obvious class differences. And it is helpful to negotiate different potential value positions between the teachers and students and promote the co-construction of meaning.

(7)PPT: Be a relatively small island, the UK's rivers are not very long.

(8)Teacher: the geographical advantage of Scotland is very suitable for the development of animal husbandry.

(9)Teacher: Ireland is rich in forest vegetation resources, known as "Emerald island".

\section{Conclusion and questionnaire}

After the empirical research of the classroom teaching discourse of the follow-up course Exploring English-speaking Countries, it is found that the proportion of appraisal meaning words in the language resources is less than $1 \%$. On the one hand, teachers should try to reduce the subjective influence of students in the process of knowledge acquisition; on the other hand, in the process of imparting knowledge, the positive attitude should be added to guide the students to participate in the construction of meaning. Engagement meaning words and graduation meaning 
words are helpful for teachers to strengthen the persuasiveness and influence of teaching contents and the co-constructing of value stand. When providing visual resources, as the main participant of teaching activities, teacher should use eye glance to transfer or provide meaning and eye contact to ask for meaning. Blackboard writing and PPT materials achieve the engagement meaning of visual modality, increase the ways of outputting knowledge. Body gesture resources can not only directly express attitudinal meaning, but also strengthen or supplement the engagement meaning and graduation meaning of language resources. Classroom space and settings reflect the alienation and unequal power relations between teachers and students. Interaction of different kinds of resources increases the achieving ways of discourse meanings, and make appraisal meaning to integrate and expand.

Table 2 appraisal meaning construction framework of classroom teaching

Appraisal meaning construction of classroom teaching

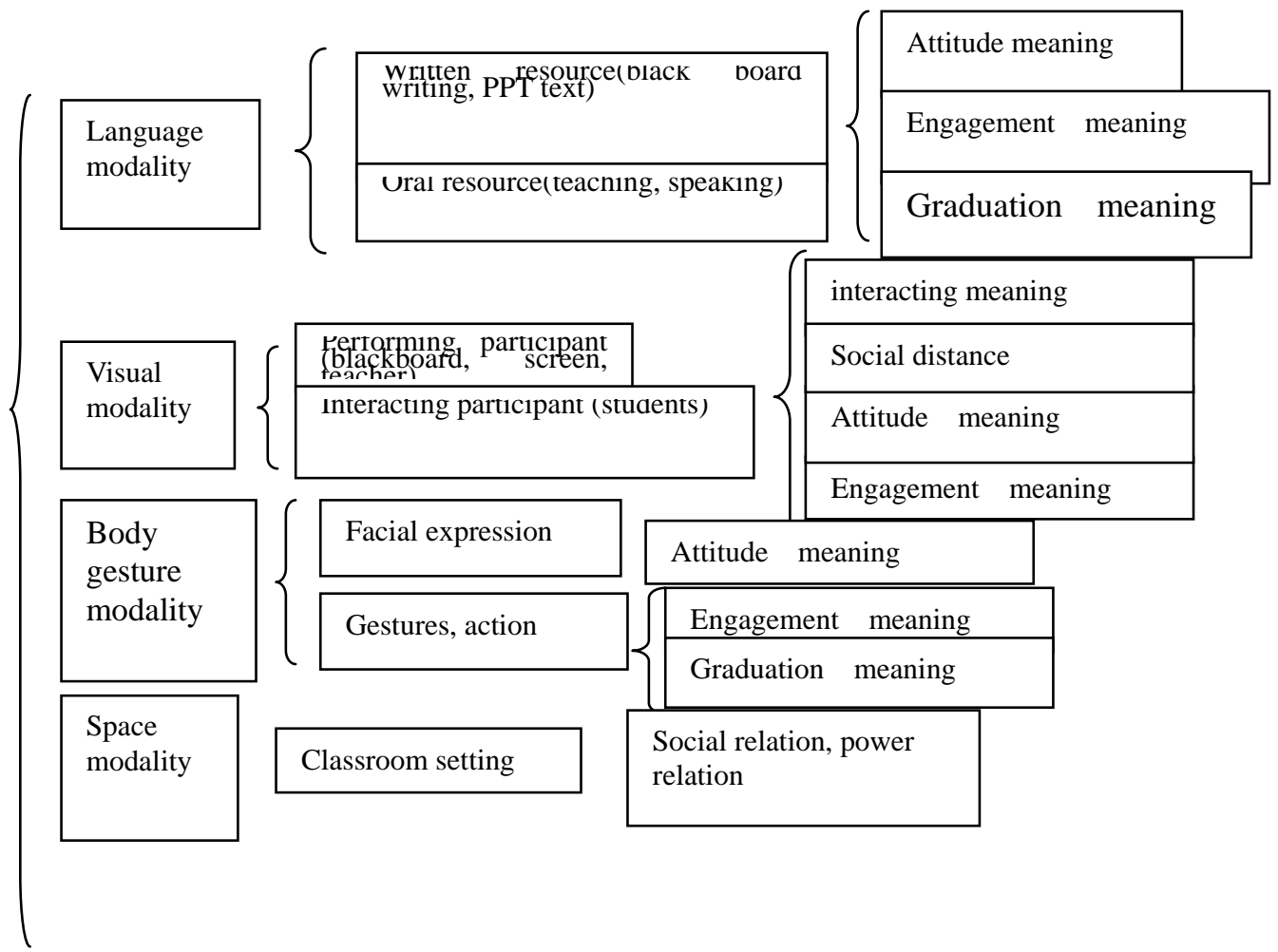

From the feedback of the questionnaire survey, 186 questionnaires were sent out, and 175 valid questionnaires were collected. The average score of the students in the teaching class is 93.8 points. 97\% of the students think that teacher's teaching language is vivid and interesting; $90 \%$ of the students think that the classroom atmosphere is relaxed; $89 \%$ of the students hope to control the number of people in the class below 100 people; $85 \%$ of the students hope that teachers can appropriately use multimedia resources; $46 \%$ of the students hope that teachers can give appropriate personal comments when imparting knowledge,; $60 \%$ of the students think it is appropriate to keep a certain social distance to teachers; $52 \%$ of the students hope to cooperate with the teacher. The survey results illustrate that the appraisal meaning that teacher express through language modality and gesture modality has positive significance in guiding students involve in meaning co-construction; Blackboard writing and PPT resources enrich the visual modality which is can stimulate students' interest in learning; but in terms of space modality, the situation of over big classroom and too many students is no conducive to the effective development and interaction between teachers and students.

\section{Conclusion}

Modality is the created symbol resource which is molded by society and has specified cultural meaning (Kress 2010:123). In the classroom teaching discourse, language resource is the main modality. At the same time, various resources like visual modality, body gesture modality and space 
modality all involve in producing appraisal meaning. Different modality resources have their own potential and limit. As follow-up course being the expansion of students learning English, teachers need to actively put more emotion and reasonably allocate the interpersonal meaning of multimodal semiotic resources then students can be encouraged to participate in the meaning construction. According to different characteristics and interpersonal function of modalities, teachers should learn more to activate the interpersonal meaning of multi-modal resources and mobilize students to participate in meaning construction which can finally promote the follow-up English curriculum construction.

\section{Acknowledgements}

In this paper, the research was sponsored by Teaching and Researching Project of Hubei Province (Project No. 2016322)

\section{References}

[1] Introduction to multimodal analysis. Machin,D. . 2007

[2] A Pedagogy of Multiliteracies: Designing Social Futures. The New London Group. Harvard Education Letter . 1996

[3]Multimodality in the TESOL Classroom: Exploring Visual-Verbal Synergy. Terry Royce. Tesol Quarterly . 2002

[4] Multimodal Transcription and Text Analysis. Baldry, A. P,Thibault, P. J. . 2006

[5] Types of process in action [J] . RADAN MARTINEC. Semiotica . 2009 (3-4)

[6] Towards a systemic functional analysis of multisemiotic mathematics texts[J] . KAY O’HALLORAN. Semiotic . 2009 (1-2) 